\title{
Chondromodulin-I suppresses tumorigenesis of human osteosarcoma cells
}

\author{
XIANGBO LIN ${ }^{1,2}$, LIJUN WANG ${ }^{3}$ and FAMING WANG ${ }^{4}$ \\ ${ }^{1}$ Department of Orthopedics, Rizhao People's Hospital, Rizhao, Shandong 276826; \\ ${ }^{2}$ Department of Orthopedics, Shanghai Changzheng Hospital, Second Military Medical University, \\ Shanghai 200003; ${ }^{3}$ Department of Neurosurgery, Rizhao People's Hospital, Rizhao, Shandong 276826; \\ ${ }^{4}$ Department of Orthopedics, Wulian People's Hospital, Rizhao, Shandong 262300, P.R. China
}

Received October 5, 2016; Accepted August 3, 2017

DOI: $10.3892 / \mathrm{mmr} .2017 .7629$

\begin{abstract}
Osteosarcoma is the most common type of bone cancer, and accounts for $\sim 3 \%$ of cancers that occurring in children. Chondromodulin-I (ChM-I) is a $25 \mathrm{kDa}$ glycoprotein that is expressed mainly in cartilage. ChM-I demonstrates anti-angiogenic activity and has been suggested to inhibit endothelial cells from invading cartilage, and then has been shown to be an inhibitor of tumorigenesis. However, it remains unclear if ChM-I has any direct anti-tumorigenesis role on osteosarcoma. Therefore, the present study aimed to identify whether ChM-I has any direct inhibit effect on human osteosarcoma cells. A bromodeoxyuridine incorporation assay was performed on the Saos-2 human osteosarcoma cell line treated with or without recombinant human ChM-I, to evaluate its impact on DNA synthesis. An adenovirus carrier for the expression of ChM-I was constructed and transfected into tumor cells in vitro to evaluate the effect of ChM-I on tumor cells. Additionally, ChM-I was knocked down by using small interfering RNA to downregulate the expression of ChM-I. Cell invasion, migration and cell-colony formation assays, and xenograft tumor experiments were performed to evaluate the effects of ChM-I on tumor cells in vitro and in vivo. The results demonstrated that ChM-I could suppress DNA synthesis of human osteosarcoma cells, and it also exerted an inhibitory effect on the proliferation and colony formation abilities of human osteosarcoma cells. In addition, ChM-I inhibited cell invasion and migration in vitro and suppressed osteosarcoma cell growth significantly in vivo. In conclusion, ChM-I directly suppressed the proliferation and growth of osteosarcoma cells
\end{abstract}

Correspondence to: Dr Lijun Wang, Department of Neurosurgery, Rizhao People's Hospital, 126 Tai An Road, Dong Gang, Rizhao, Shandong 276826, P.R. China

E-mail: wanglijunrizhao@126.com

Key words: chondromodulin-1, human osteosarcoma cells, invasion, migration, growth, proliferation, anti-vascularization, antitumor in an anchorage-independent manner, and may therefore be a promising drug for the treatment of osteosarcoma.

\section{Introduction}

Osteosarcoma most often affects the long bones, such as those in the arms and legs, and has an annual incidence worldwide of $\sim$ one to three cases per million $(1,2)$. It has a bimodal distribution with peaks in the second decade of life and late adulthood, and arises primarily in pre-teens and teens, and is the third most common cancer in adolescence, and the most common primary bone tumor in children $(3,4)$. It has been reported that osteosarcoma has a higher incidence in males (5.4 per million males/year) than in females (4.0 per million females/year) (5). The typical clinical presentation of osteosarcoma includes pathologic fractures, swelling and onset of pain in the affected bone, where the pain is sufficiently intense to wake the patient from sleep. $\sim 15$ to $20 \%$ of patients will have clinically detectable metastases. The most common site of metastasis occurs in the lung and bone is the second most common metastasis site (6).

Cancer deaths caused by bone and joint malignancy account for $8.9 \%$ of all childhood and adolescent cancer deaths, and the death rates of osteosarcoma have been declining by $\sim 1.3 \%$ per year. The overall 5-year survival rate for osteosarcoma is $68 \%$, and the older patients have the poorest survival; however, it is not correlated with gender (5). Depending on the cancer stage, osteosarcoma treatment includes surgery and chemotherapy (7). Complete surgical excision and chemotherapy regimens are associated with survival outcome significantly. In addition, tumor staging, tumor size, anatomic location and presence of metastases, as well as local recurrence are important to ensure an optimum prognosis (5).

Because osteosarcoma cells secrete various growth factors that induce angiogenesis to supply nutrition for their own growth, agents that inhibit angiogenesis are good candidates for antitumor drugs (8-10). Chondromodulin-I (ChM-I), a 25-kDa glycoprotein purified from bovine epiphyseal cartilage on the basis of growth-promoting activity for chondrocytes, was recently identified as an angiogenesis inhibitor $(11,12)$. Human ChM-I cDNA revealed that the mature protein consists of 120 amino acids and is coded as the 
C-terminal part of a larger transmembrane precursor $(13,14)$. It is reported that ChM-I is a homologous inhibitor and is predominantly expressed in the avascular region of cartilage (15).

It is well known that ChM-I exerts anti-vascularization action; therefore, it is considered to have antitumor properties (16). Tsai et al (17) indicated that ChM-I exhibits vascular targeting activity that is associated with the induction of DR5-mediated endothelial cell apoptosis through p53 upregulation, which suggests its potential as an antivascular and antitumor therapeutic agent. Hsu et al (18) reported that CHM-I is a potent inducer of apoptosis, which serves a role in the anticancer activity of CHM-I. However, it has remained unclear whether ChM-I exerts any direct antitumor effect on osteosarcoma cells. Therefore, the present study aimed to evaluate the direct effects of ChM-I on osteosarcoma cells. The current study indicated that ChM-I directly suppresses the proliferation of osteosarcoma cells in vitro, and also inhibits osteosarcoma cell growth in vivo.

\section{Materials and methods}

Animals and patients. All animal experimental procedures in this study were approved by the Ethics Committee of the Second Military Medical University (Shanghai, China).

Human articular cartilage used in this study was used to harvest the ChM-I gene, and was obtained from the femoral condyles of patients undergoing knee joint replacement surgery at Shanghai Changzheng Hospital, Second Military Medical University. Written informed consent was obtained from all participants prior to the study. A total of 6 patients were recruited to the present study (male, 65 years). After surgically removing cartilage from the knee joint, the chondrocytes were harvested by enzymatic digestion.

Cell culture. The Saos-2 human osteosarcoma cell line was purchased from the Shanghai Biological Cell Bank, Chinese Academy of Sciences (Shanghai, China). Cells were cultured for 1 week (after 2 passages) in Dulbecco's modified Eagle's medium (DMEM; Gibco; Thermo Fisher Scientific Inc., Waltham, MA, USA) supplemented with $10 \%$ fetal bovine serum (FBS) in a humidified atmosphere containing $5 \% \mathrm{CO}_{2}$ at $37^{\circ} \mathrm{C}$.

Small interfering RNA (siRNA). siRNA transfection was used to knock down ChM-I mRNA expression in Saos-2 cells. The siRNA sequences used were: 5'-UGGAUUUAUCCUACAG AUGCA-3'; 5'-CAUCUGUAGGAUAAAUCCAUA-3'. siRNA transfection was performed according to the protocol of a previous study (19).

ChM-I overexpression. A PcDNA3.1(+)-ChM-I plasmid was constructed to overexpress ChM-I, and a ChM-I cDNA expression vector (pcDNA3.1(+)-ChM-I) was constructed by Shanghai GeneChem Co., Ltd. (Shanghai, China). In brief, the ChM-I gene was generated by polymerase chain reaction (PCR) amplification from cartilage tissue, and the plasmid pcDNA3.1(+)-ChM-I was generated according to the cDNA sequence from GenBank (National Institutes of Health, Bethesda, MD, USA). The plasmid pcDNA3.1(+) was extracted with a Qiagen extraction kit (Qiagen China Co., Ltd., Shanghai, China) according to the manufacturer's protocol. The PCR product was subcloned into the BamHI (Clontech Laboratories, Inc., Mountain View, CA, USA) and HindIII (Clontech Laboratories, Inc.) sites of pcDNA3.1 plasmid by T4 ligase (Clontech Laboratories, Inc.). The recombinant plasmid was transfected into $293 \mathrm{~T}$ cells using Lipofectamine ${ }^{\circledR} 2000$ (Invitrogen; Thermo Fisher Scientific, Inc.). Adenoviruses were plaque-purified and propagated in 293T cells. The viral lysates were purified and concentrated through two cycles of $\mathrm{CsCl} 2$ (Sigma-Aldrich; Merck KGaA, Darmstadt, Germany) step gradients, and the reconstructed adenovirus was divided into several aliquots and stored at a titer of $1.0 \times 10^{9}$ plaque-forming units $/ \mu 1$ at $80^{\circ} \mathrm{C}$ according to a previous study (20).

Reverse transcription-quantitative PCR (RT-qPCR). RT-qPCR was used to analyze ChM-I mRNA expression levels in the ChM-I overexpression and siRNA groups, according to a previous study (20). RNA extraction buffer (catalog no. Z3051; Promega Corporation, Madison, WI, USA), the miScript II RT kit (catalog no. 218160; Qiagen China Co., Ltd.) and the Quntititect $^{\mathrm{TM}}$ SYBR-Green PCR Reagent kit (Qiagen China Co., Ltd.) were used. The primer sequences for ChM-I were as follows: Forward, 3'-ATCAGCAGGAAGGGGAAAGC-5' and reverse, 3'-TGGTCCCATCAGCATCAACC-5', product size 308 bp. Primer sequences for $\beta$-actin were: Forward, 3'-3'-TCCATCATGAAGTGTGACGT-5' and reverse, 3'-CTC AGGAGGAGCAATGATCT-5', product size 161 bp. PCR was performed on the corresponding cDNA synthesized from each sample in triplicate with the GeneAmp 5700 system (Applied Biosystems; Thermo Fisher Scientific. Inc.), according to the manufacturer's protocol. Thermocycling conditions for PCR were as follows: An initial predenaturation step at $95^{\circ} \mathrm{C}$ for $15 \mathrm{~min}$, followed by 35 cycles of denaturation at $94^{\circ} \mathrm{C}$ for $30 \mathrm{sec}$, annealing at $50^{\circ} \mathrm{C}$ for $30 \mathrm{sec}$, extension at $72^{\circ} \mathrm{C}$ for $1 \mathrm{~min}$ and a final extension step at $72^{\circ} \mathrm{C}$ for $10 \mathrm{~min}$. mRNA expression levels were normalized to $18 \mathrm{~S}$ rRNA, and data was analyzed using the $2^{-\Delta \Delta C q}$ method (21).

Western blotting. Western blot analysis was performed to analyze the expression of ChM-I expression in the overexpression and siRNA groups. Total protein from cultured cells were lysed using lysis buffer supplemented with phenylmethylsulfonyl fluoride (1 mM) on ice as described previously (19). The protein concentration in each sample was determined using a bicinchoninic acid assay kit (Thermo Fisher Scientific, Inc.). A total of $20 \mu \mathrm{g}$ protein was separated by $10 \%$ SDS-PAGE and then transferred to a polyvinylidene difluoride membrane (EMD Millipore, Billerica, MA, USA). Membranes were blocked with $5 \%$ non-fat milk powder at room temperature for $1 \mathrm{~h}$ and incubated for $1 \mathrm{~h}$ with primary antibodies at room temperature, including a chondromodulin-I antibody (catalog no. NBP1-59348; Novus Biologicals, LLC, Littleton, LO, USA) and a GAPDH antibody (catalog no. NBP300-221H, Novus Biologicals, LLC) at 1:1,000 dilution. After three 10-min washes in TBS with Tween-20, membranes were incubated with secondary antibodies labeled with horseradish peroxidase (catalog no. NBP600-894; Novus Biologicals, LLC; 1:1,000) for $1 \mathrm{~h}$ at room temperature. At last, the signals were detected using an Enhanced Chemiluminescence kit (Pierce; Thermo 
Fisher Scientific, Inc.) and the membranes were scanned and analyzed to determine the protein expression. Image $\mathbf{J}$ software version 1.46 (National Institutes of Health, Bethesda, MD, USA) was used for densitometric analysis. The protein expression was normalized to an endogenous reference GAPDH and relative to the control.

DNA synthesis assay. A bromodeoxyuridine (BrdU) incorporation assay was used to assess the proliferation of Saos-2 cells. Cells were harvested with trypsin/EDTA and suspended in DMEM containing 10\% FBS. The cells were seeded at $2 \times 10^{4}$ cells $/ \mathrm{ml}$ into a 96 -well plate $(100 \mu \mathrm{l} /$ well $)$ and cultured for $48 \mathrm{~h}$ at $37^{\circ} \mathrm{C}$. Following medium replacement with medium containing either 15 or $30 \mu \mathrm{g} / \mathrm{ml}$ recombinant human (rh)ChM-I, $20 \mu 11 \mathrm{X} \mathrm{BrdU}$ was added prior to incubation of the cells for $12,24,36$ or $48 \mathrm{~h}$ at room temperature. Cells were labeled with BrdU during the last $3 \mathrm{~h}$ of this incubation. The medium was then replaced with one containing either 15 or $30 \mu \mathrm{g} / \mathrm{ml} \mathrm{rhChM}-\mathrm{I}$, BrdU was added, and the cells were cultured for 12, 24, 36 or $48 \mathrm{~h}$. BrdU incorporation by the cells was measured at each time-point using a cell proliferation ELISA BrdU colorimetric kit (catalog no. ab126556; Abcam, Cambridge, UK) according to the manufacturer's protocol, in triplicate. Quantification of BrdU was performed by measuring the absorbance at $450 \mathrm{~nm}$, referenced at $655 \mathrm{~nm}$ using a DU 800 spectrophotometer (Beckman Coulter, Inc., Brea, CA, USA).

In vitro cell proliferation assay. A Cell Counting Kit-8 (CCK-8; Dojindo Laboratories, Kumamoto, Japan) was used to determine cell proliferation as described previously (http://www. dojindo.com). For each group, a 200- $\mu 1$ suspension containing $10^{4}$ cells was added per well into a 96-well plate and incubated overnight at $37^{\circ} \mathrm{C}$. Following this, culture medium was removed and fresh medium (100 $\mu \mathrm{l} / \mathrm{well})$ and $10 \mu \mathrm{l}$ CCK- 8 solution were added, and cells were incubated for $4 \mathrm{~h}$ at $37^{\circ} \mathrm{C}$. On days 1 , 3,5 and 7, the absorbance of the supernatant was measured spectrophotometrically at $450 \mathrm{~nm}$ (Beckman Coulter, Inc.). Cell counts were determined using a calibration curve and a Nikon E400 microscope (Nikon Corporation, Tokyo, Japan), and the experiments were performed in triplicate.

Cell invasion and migration assays. Transwell (8- $\mu \mathrm{m}$ pore size, Corning Life Sciences, Corning, NY, USA) was use to assessed cell invasion and migration capacity. According to the manufacturer's protocol, $2 \times 10^{4}$ cells suspended in serum-free medium were seeded into Transwell inserts either coated (for invasion assay) or uncoated (for migration assay) with growth factor-reduced Matrigel (BD Biosciences, Franklin Lakes, NJ, USA) (19). Bottom wells were incubated with complete medium for $24 \mathrm{~h}$, and the invaded cells were fixed with $4 \%$ paraformaldehyde and stained with a crystal violet solution at room temperature for $20 \mathrm{~min}$, and the number of penetrating cells was counted using a Nikon E400 microscope (Nikon Corporation).

Scratch wound assay. Cells migration was measured by the scratch wound assay (22). Cells were plated at a density of $5 \times 10^{5}$ cells to 6-well-plates (Corning Costar, Kaiserslautern, Germany) $24 \mathrm{~h}$ prior to the scratch. A cell free area spanning approximately $500 \mu \mathrm{m}$ in diameter was scratched using a crystal $10 \mu \mathrm{l}$ pipette tip after $24 \mathrm{~h}$. The wells were washed with medium to remove cellular debris. Cells were incubated with DMEM without FBS. After 24 h, Gap width was measured using ImageJ v1.46 (Wayne Rasband National Institutes of Health, Bethesda, MD, USA).

Colony-formation assay. The colony-formation assay was performed to assess the anchorage-dependent proliferation of cells. The log-phase cells were harvested, and cultured in 6-well dishes as described previously (23). The number of colonies was stained with Coomassie Brilliant Blue (Sigma-Aldrich; Merck KGaA) at room temperature for $15 \mathrm{~min}$, and the visible colonies were counted after 1,2 and 3 weeks of incubation under a phase contrast microscope. This assay was performed in triplicate at least.

In vivo tumorigenicity assay. For in vivo assessment of tumor formation, nude BALB/c athymic mice (male, aged 6 weeks, $20 \mathrm{~g}$ ) purchased from the Shanghai Laboratory Animal Centre (Shanghai, China) were subcutaneously injected with $10^{7}$ cultured human Saos-2 osteosarcoma cells suspended $500 \mu \mathrm{l}$ sterile PBS in to evaluate the effect of ChM-I on tumor growth in vivo. Once tumors reached a volume of $200 \mathrm{~mm}^{3}$, mice ( $\mathrm{n}=6 /$ group) were injected with $5 \mathrm{mg} / \mathrm{kg}$ recombinant human (rh)ChM-I (experimental group) or $500 \mu \mathrm{l}$ PBS (control group). Mice received injections twice a week for 5 weeks. Tumor length and width were measured with calipers over a period of 5 weeks. The tumor volume was calculated as (length $\mathrm{x}$ width $\left.{ }^{2}\right) / 2$. The mice were checked daily for up to 3 weeks for tumor formation (24). Mice were housed at a temperature of $25 \pm 12^{\circ} \mathrm{C}$, humidity of $55 \pm 5 \%$ and $12 \mathrm{~h}$ light dark cycle. Food and water were freely available.

Statistical analysis. The data are presented e.g., as the mean \pm standard deviation. One-way analysis of variance followed by Tukey's post hoc test was performed to analyze the differences between groups followed by Turkey post hoc test. $\mathrm{P}<0.05$ was considered to indicate a statistically significant difference. SPSS software version 18.0 (SPSS, Inc., Chicago, IL, USA) was used for analysis.

\section{Results}

ChM-I expression is upregulated by overexpression and downregulated by siRNA. As demonstrated by RT-qPCR and western blotting, the expression of ChM-I was increased in the Ad-ChM-I group compared with the control group $(\mathrm{P}<0.05)$, while the expression of ChM-I was inhibited significantly by siRNA targeted to ChM-I (P<0.05; Fig. 1).

ChM-I inhibits DNA synthesis of osteosarcoma cells. The effect of rhChM-I protein on DNA synthesis in osteosarcoma cells was evaluated by a BrdU incorporation assay. The results demonstrated that 15 and $30 \mu \mathrm{g} / \mathrm{ml} \mathrm{BrdU}$ suppressed DNA synthesis significantly at 24,36 and $48 \mathrm{~h}(\mathrm{P}<0.05$; Fig. 2$)$.

ChM-I suppresses tumor growth in vivo. In order to evaluate the effect of ChM-I on tumor growth in vivo, nude BALB/c athymic mice were injected with human osteosarcoma cells. 

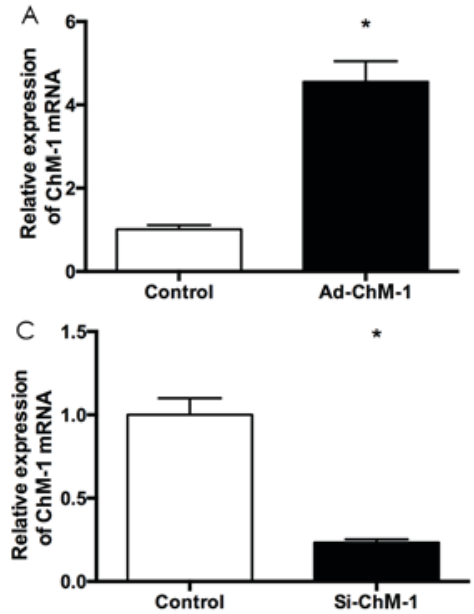

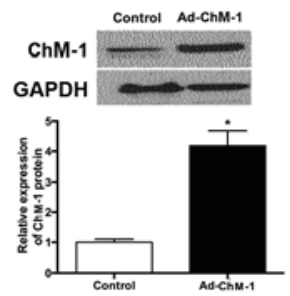

D

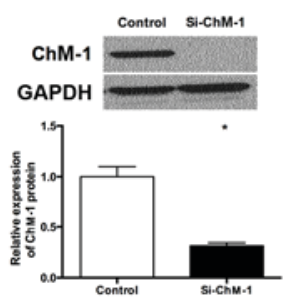

Figure 1. ChM-I expression in Saos-2 cells. (A) mRNA and (B) protein expression levels of ChM-I following overexpression using pcDNA3.1(+)-ChM-I (C) mRNA and (D) protein expression levels of ChM-I following knockdown with siRNA. "P<0.05. si, small interfering; ChM-I, chondromodulin-1. The data are presented as the mean \pm standard deviation.

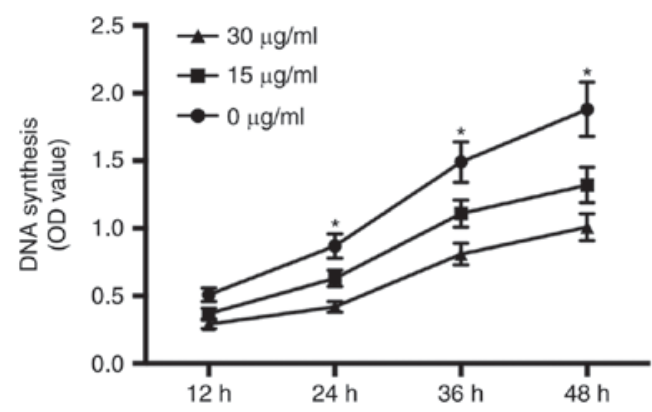

Figure 2. Chondromodulin-1 inhibits DNA synthesis. The BrdU incorporation assay demonstrated that 15 and $30 \mu \mathrm{g} / \mathrm{ml}$ BrdU suppresses DNA synthesis in Saos-2 osteosarcoma cells significantly. ${ }^{*} \mathrm{P}<0.05$. BrdU, bromodeoxyuridine; $\mathrm{OD}$, optical density. The data are presented as the mean \pm standard deviation.

Upon reaching a volume of $200 \mathrm{~mm}^{3}$, the tumors were injected with rhChM-I protein (experimental group) or PBS (control group). The tumors grew exponentially in the PBS group, while the tumor in the experimental group reduced significantly at 14 days after injection, and were further reduced in a time-dependent manner (Fig. 3).

ChM-I suppresses cells proliferation in vitro. To assess the effect of ChM-I on the proliferation of human Saos-2 osteosarcoma cells in vitro, cells transfected with pcDNA3.1(+)-ChM-I and cells knocked down using siRNA were used. The results demonstrated that ChM-I overexpression suppressed cell proliferation (Fig. 4A; $\mathrm{P}<0.05$ ), while ChM-I siRNA enhanced cell proliferation (Fig. 4B; $\mathrm{P}<0.05$ ) in vitro.

ChM-I suppresses the colony formation ability of human osteosarcoma cells in vitro. In order to assess the effects of ChM-I on the growth of osteosarcoma cells, an agarose-based colony formation assay was performed according to a previous study (25). The results demonstrated that the overexpression of ChM-I suppressed the colony formation ability of human osteosarcoma cells (Fig. 5A; P<0.05), while ChM-I knockdown enhanced the colony formation ability of human osteosarcoma cells (Fig. 5B; $\mathrm{P}<0.05$ ).

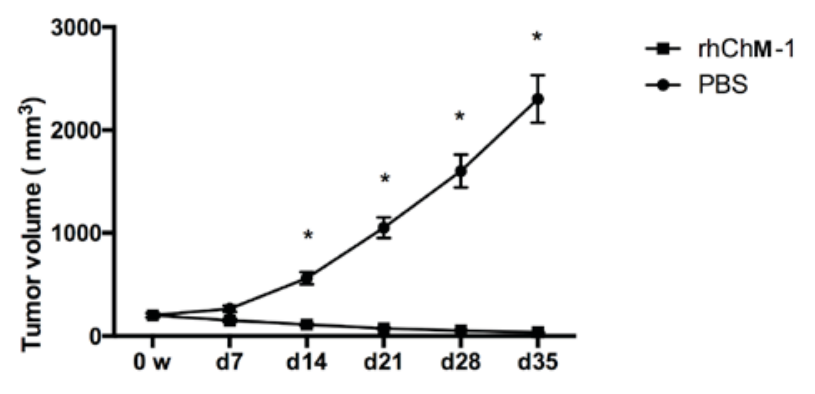

Figure 3. ChM-I suppresses tumor growth in vivo. Nude BALB/c athymic mice were injected with human osteosarcoma cells to evaluate the effect of ChM-I on tumor growth in vivo. ${ }^{*} \mathrm{P}<0.05$. ChM-I, chondromodulin-1; rh, recombinant human. The data are presented as the mean \pm standard deviation.

ChM-I suppresses osteosarcoma cell migration and invasion. As presented in Fig. 6, compared with control cells, cells in the ChM-I overexpression group demonstrated decreased cell migration in the scratch wound assay, while cells in the ChM-I knockdown group demonstrated increased migration ability. The results were further confirmed by a three-dimensional cell migration assay and an invasion assay, which demonstrated that ChM-I overexpression resulted in a significant reduction in the migration and invasion ability, while ChM-I knockdown resulted in a significant increase in migration and invasion ability (Fig. 6).

\section{Discussion}

Osteosarcoma, the most common bone tumor occurs in children and adolescents, is an aggressive and highly malignant cancer $(26,27)$. It occurs slightly more commonly in male than female patients, and has a predilection for the metaphyseal regions adjacent to physes with the greatest growth in the distal femur, proximal tibia and proximal humerus $(28,29)$. In $\sim 15-20 \%$ of patients, osteosarcoma has spread by the time it is diagnosed (30). Therefore, early diagnosis and early treatment serves a very important role in the prognosis of patients. Certain methods have been used to cure this disease, such as 

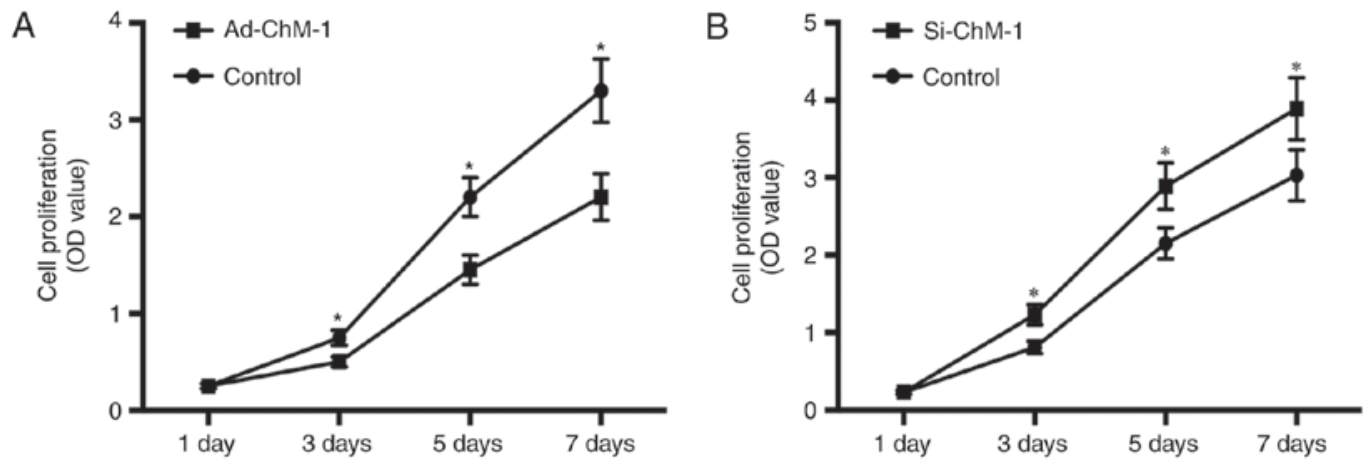

Figure 4. ChM-I suppresses cell proliferation in vitro. Cell proliferation following (A) ChM-I overexpression using pcDNA3.1(+)-ChM-I and (B) ChM-I knockdown using ChM-I-siRNA. "P<0.05. ChM-I, chondromodulin-1; siRNA, small interfering RNA; OD, optical density. The data are presented as the mean \pm standard deviation.
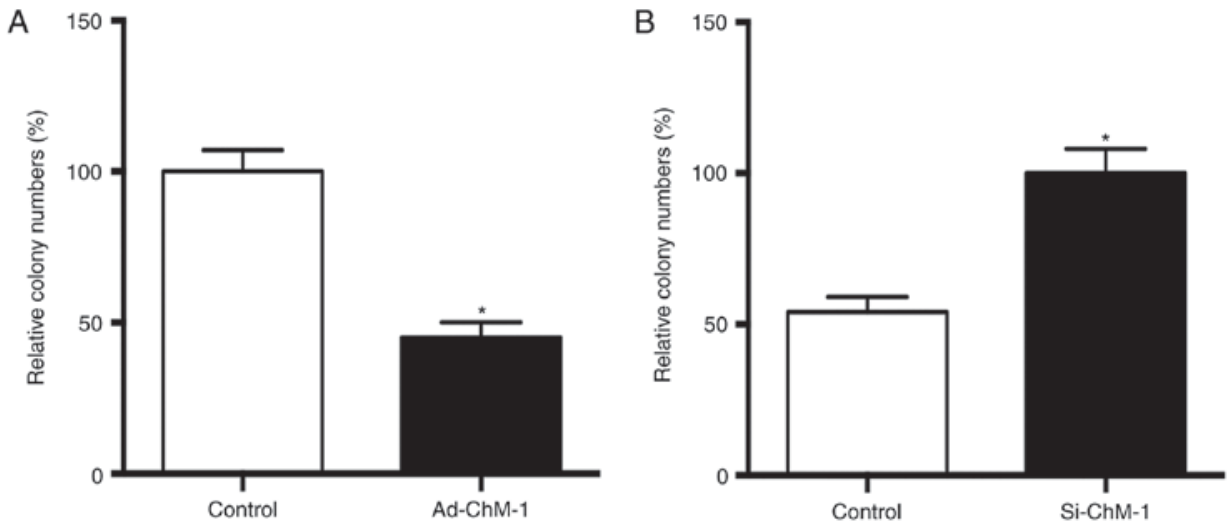

Figure 5. ChM-I suppresses the colony formation ability of osteosarcoma cells. Colony formation following (A) ChM-I overexpression using pcDNA3.1(+)-ChM-1 and (B) ChM-1 knockdown using ChM-1-siRNA. "P<0.05. ChM-1, chondromodulin-1; siRNA, small interfering RNA. The data are presented as the mean \pm standard deviation.
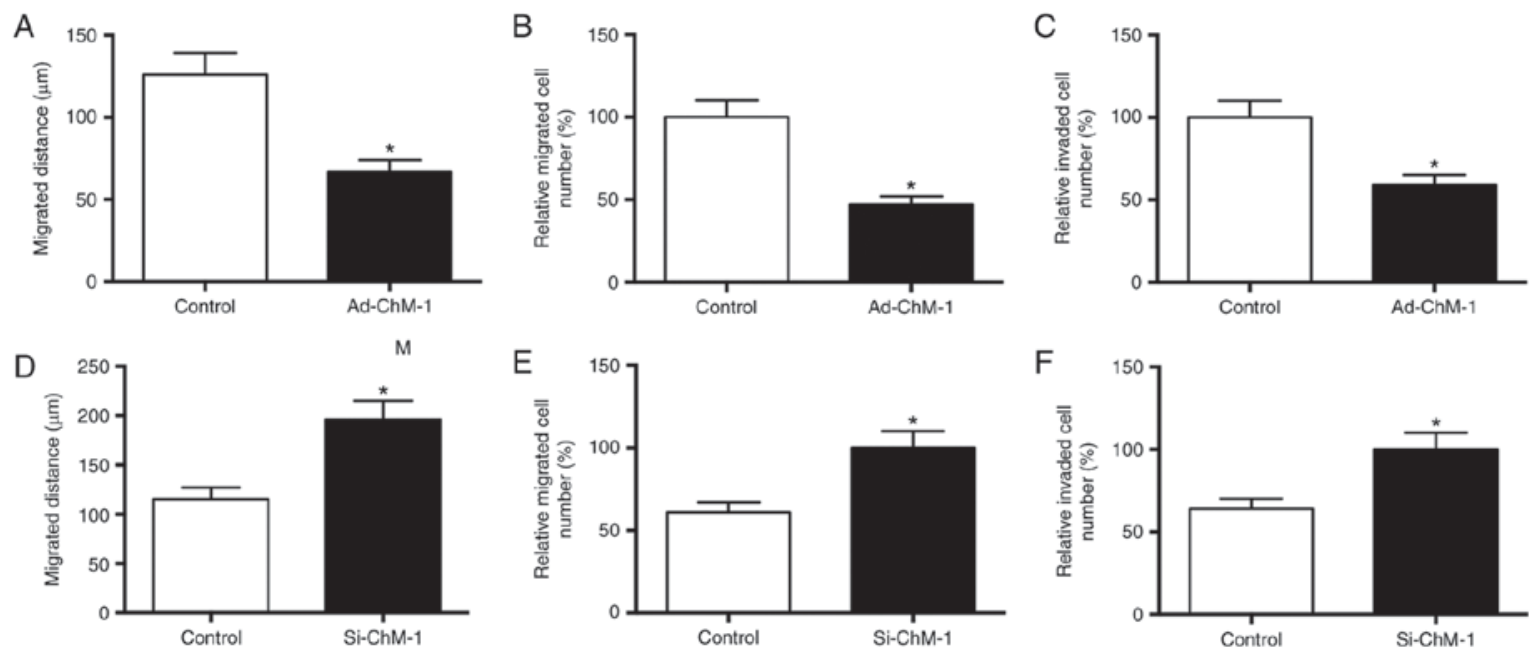

Figure 6. Chondromodulin 1 suppresses osteosarcoma cell migration and invasion. (A) Migratory distance, (B) number of migrated cells and (C) number of invaded cells in osteosarcoma cells overexpressing ChM-1. (D) Migratory distance, (E) number of migrated cells and (F) number of invaded cells in osteosarcoma cells with ChM-1 knocked down. "P $<0.05$. ChM-1, chondromodulin-1; siRNA, small interfering RNA. The data are presented as the mean \pm standard deviation.

surgery, and chemo- and radiotherapy, which depends on the stage of tumor development (31-33). Angiogenesis is considered to serve a crucial role in tumor growth, tumor propagation and metastasis formation; tumors cannot grow beyond $1-2 \mathrm{~mm}$ in diameter without angiogenesis (34). Therefore, anti-angiogenic drugs and treatments have been developed to inhibit the formation of new blood vessels and block the blood supply of tumors in order to inhibit or cure tumors $(35,36)$. 
It has been reported that ChM-I, a 25-kDa glycoprotein purified from cartilage on the basis of growth-promoting activity for chondrocytes, was recently identified as an angiogenesis inhibitor $(13,14)$. ChM-I promotes growth and colony formation of cultured chondrocytes, but inhibits angiogenesis in vitro and in vivo. A previous study demonstrated that ChM-I inhibited vascular invasion into cartilage that was ectopically induced by demineralized bone matrix in nude mice, leading to the suppression of replacement of cartilage by bone in vivo (13). Klinger et al (37) revealed that adeno-associated virus (AAV) vectors carrying ChM-I complementary DNA (AAV-ChM-I) efficiently produced ChM-I, which had strong antiangiogenic effects, as verified by the inhibition of tube formation of endothelial cells. Additionally, previous studies have demonstrated that ChM-I exerts an antitumor effect, which may be based on the effect of angiogenesis inhibition $(16,38)$. However, to the best of our knowledge, no previous studies have demonstrated the effect of ChM-I on osteosarcoma. Therefore, the present study aimed to determine the possible direct antitumor effects of ChM-I in osteosarcoma.

The results demonstrated that ChM-I not only has the ability to suppress angiogenesis, but also to suppress tumor cell proliferation in vitro and inhibit tumor growth in vivo. Zhang et al (19) also reported that ChM-I functions as a tumor suppressor in gastric adenocarcinoma, which indicated that ChM-I is a potential tumor suppressor in gastric cancer, suggesting that it may be useful as a biomarker for the treatment and prognosis of gastric cancer.

In the present study, the results of the BrdU incorporation assay demonstrated that ChM-I inhibits DNA synthesis of osteosarcoma cells. ChM-I was demonstrated to exhibit antitumor effects based on direct inhibition of tumor-cell growth. The results of the CCK-8 assay indicated that overexpression of ChM-I inhibited the proliferation of human osteosarcoma cells significantly, while ChM-I knockdown enhanced the proliferation of human osteosarcoma cells. The direct antitumor effects of ChM-I on human osteosarcoma cells were further proven by a colony formation assay. The agarose-based clonogenic assay demonstrated that ChM-I inhibited the proliferation of osteosarcoma cells significantly. In a study by Shao et al (20), they transfected ChM-I into human breast cancer cells, and observed that it inhibited the growth of human breast cancer cells. In the present study, the in vivo xenograft study demonstrated that ChM-I inhibited osteosarcoma growth in nude mice. The anti-cancer efficacy of ChM-I may be due to its marked impact on the tumor microenvironment with additional direct suppression of tumor cell proliferation, which has been demonstrated to be exerted via activation of transforming growth factor $\beta$ in tumor cells overexpressing this protein (39).

In conclusion, the present study demonstrated that ChM-I exerts antitumor effects by directly suppressing the proliferation and growth of osteosarcoma cells. The direct antitumor effects and anti-angiogenic effects make ChM-I a promising potential drug in treating osteosarcoma.

\section{Acknowledgements}

The present study was supported by the Rizhao Committee of Science and Technology of Shandong, China (grant no. 201539).

\section{References}

1. Kansara M, Teng MW, Smyth MJ and Thomas DM: Translational biology of osteosarcoma. Nat Rev Cancer 14: 722-735, 2014.

2. Parkin DM, Pisani P and Ferlay J: Global cancer statistics. CA Cancer J Clin 49: 33-64, 1999.

3. Bielack S, Kempf-Bielack B, Von Kalle T, Schwarz R, Wirth T, Kager L and Whelan J: Controversies in childhood osteosarcoma. Minerva Pediatr 65: 125-48, 2013.

4. Moore DD and Luu HH: Osteosarcoma. Cancer Treat Res 162: 65-92, 2014.

5. Ottaviani G and Jaffe N: The epidemiology of osteosarcoma. Cancer Treat Res 152: 3-13, 2009.

6. Isakoff MS, Bielack SS, Meltzer P and Gorlick R: Osteosarcoma: Current treatment and a collaborative pathway to success. J Clin Oncol 33: 3029-3035, 2015.

7. Fan Z, Patel S, Lewis VO, Guadagnolo BA and Lin PP: Should High-grade extraosseous osteosarcoma Be treated with multimodality therapy like other soft tissue sarcomas? Clin Orthop Relat Res 473: 3604-3611, 2015.

8. Jones KB, Ferguson PC, Lam B, Biau DJ, Hopyan S, Deheshi B, Griffin AM, White LM and Wunder JS: Effects of neoadjuvant chemotherapy on image-directed planning of surgical resection for distal femoral osteosarcoma. J Bone Joint Surg Am 94: 1399-1405, 2012.

9. Peng N, Gao S, Guo X, Wang G, Cheng C, Li M and Liu K: Silencing of VEGF inhibits human osteosarcoma angiogenesis and promotes cell apoptosis via VEGF/PI3K/AKT signaling pathway. Am J Transl Res 8: 1005-1015, 2016.

10. Dossi R, Frapolli R, Di Giandomenico S, Paracchini L, Bozzi F, Brich S, Castiglioni V, Borsotti P, Belotti D, Uboldi S, et al: Antiangiogenic activity of trabectedin in myxoid liposarcoma: Involvement of host TIMP-1 and TIMP-2 and tumor thrombospondin-1. Int J Cancer 136: 721-729, 2015.

11. Miura S, Kondo J, Takimoto A, Sano-Takai H, Guo L, Shukunami C, Tanaka H and Hiraki Y: The N-terminal cleavage of chondromodulin-I in growth-plate cartilage at the hypertrophic and calcified zones during bone development. PLoS One 9: e94239, 2014

12. Aoyama T, Okamoto T, Fukiage K, Otsuka S, Furu M, Ito K, Jin Y, Ueda M, Nagayama S, Nakayama T, et al: Histone modifiers, YY1 and p300, regulate the expression of cartilage-specific gene, chondromodulin-I, in mesenchymal stem cells. J Biol Chem 285: 29842-29850, 2010.

13. Hiraki Y and Shukunami C: Chondromodulin-I as a novel cartilage-specific growth-modulating factor. Pediatr Nephrol 14: 602-605, 2000.

14. Hiraki Y, Inoue H, Iyama K, Kamizono A, Ochiai M, Shukunami C, Iijima S, Suzuki F and Kondo J: Identification of chondromodulin I as a novel endothelial cell growth inhibitor. Purification and its localization in the avascular zone of epiphyseal cartilage. J Biol Chem 272: 32419-32426, 1997.

15. Yukata K, Matsui Y, Shukunami C, Takimoto A, Hirohashi N, Ohtani O, Kimura T, Hiraki Y and Yasui N: Differential expression of Tenomodulin and Chondromodulin-1 at the insertion site of the tendon reflects a phenotypic transition of the resident cells. Tissue Cell 42: 116-120, 2010.

16. Oshima Y, Sato K, Tashiro F, Miyazaki J, Nishida K, Hiraki Y, Tano Y and Shukunami C: Anti-angiogenic action of the C-terminal domain of tenomodulin that shares homology with chondromodulin-I. J Cell Sci 117: 2731-2744, 2004.

17. Tsai AC, Pan SL, Sun HL, Wang CY, Peng CY, Wang SW, Chang YL, Kuo SC, Lee KH and Teng CM: CHM-1, a new vascular targeting agent, induces apoptosis of human umbilical vein endothelial cells via p53-mediated death receptor 5 up-regulation. J Biol Chem 285: 5497-5506, 2010.

18. Hsu SC, Yang JS, Kuo CL, Lo C, Lin JP, Hsia TC, Lin JJ, Lai KC, Kuo HM, Huang LJ, et al: Novel quinolone CHM-1 induces apoptosis and inhibits metastasis in a human osterogenic sarcoma cell line. J Orthop Res 27: 1637-1644, 2009.

19. Zhang P, Wang Y, Xu P, Song S, Zhu X, Shi Z, Gao S and Feng X: Chondromodulin-1 functions as a tumor suppressor in gastric adenocarcinoma. Int J Oncol 47: 941-950, 2015.

20. Shao J, Gan L and Wang J: Transfection of chondromodulin I into human breast cancer cells and its effect on the inhibition of cancer cell growth. Mol Med Rep 13: 4303-4308, 2016.

21. Livak KJ and Schmittgen TD: Analysis of relative gene expression data using real-time quantitative PCR and the 2(-Delta Delta C(T)) method. Methods 25: 402-408, 2001. 
22. Roloff F, Ziege S, Baumgärtner W, Wewetzer K and Bicker G: Schwann cell-free adult canine olfactory ensheathing cell preparations from olfactory bulb and mucosa display differential migratory and neurite growth-promoting properties in vitro. BMC Neurosci 14: 141, 2013.

23. Franken NA, Rodermond HM, Stap J, Haveman J and van Bree C: Clonogenic assay of cells in vitro. Nat Protoc 1: 2315-2319, 2006.

24. Li P, Chen X, Su L, Li C, Zhi Q, Yu B, Sheng H, Wang J, Feng R, Cai $Q$, et al: Epigenetic silencing of miR-338-3p contributes to tumorigenicity in gastric cancer by targeting SSX2IP. PLoS One 8: e66782, 2013.

25. Shingu T, Holmes L, Henry V, Wang Q, Latha K, Gururaj AE, Gibson LA, Doucette T, Lang FF, Rao G, et al: Suppression of RAF/MEK or PI3K synergizes cytotoxicity of receptor tyrosine kinase inhibitors in glioma tumor-initiating cells. J Transl Med 14: 46, 2016.

26. Yang Z, Li X, Yang Y, He Z, Qu X and Zhang Y: Long noncoding RNAs in the progression, metastasis, and prognosis of osteosarcoma. Cell Death Dis 7: e2389, 2016.

27. PDQ Pediatric Treatment Editorial Board: Osteosarcoma and Malignant Fibrous Histiocytoma of Bone Treatment (PDQ $\left.{ }^{8}\right)$ In: PDQ Cancer Information Summaries [Internet]. Health Professional Version. National Cancer Institute (US), Bethesda, 2002.

28. Abarrategi A, Tornin J, Martinez-Cruzado L, Hamilton A, Martinez-Campos E, Rodrigo JP, González MV, Baldini N, Garcia-Castro J and Rodriguez R: Osteosarcoma: Cells-of-Origin, cancer stem cells, and targeted therapies. Stem Cells Int 2016 3631764, 2016.

29. Li CJ, Liu XZ, Zhang L, Chen LB, Shi X, Wu SJ and Zhao JN Advances in Bone-targeted drug delivery systems for neoadjuvant chemotherapy for osteosarcoma. Orthop Surg 8: 105-110, 2016.
30. Friebele JC, Peck J, Pan X, Abdel-Rasoul M and Mayerson JL: Osteosarcoma: A meta-analysis and review of the literature. Am J Orthop (Belle Mead NJ) 44: 547-553, 2015.

31. Li S, Sun W, Wang H, Zuo D, Hua Y and Cai Z: Research progress on the multidrug resistance mechanisms of osteosarcoma chemotherapy and reversal. Tumour Biol 36: 1329-1338, 2015.

32. Dass CR and Choong PF: Gene therapy for osteosarcoma: Steps towards clinical studies. J Pharm Pharmacol 60: 405-413, 2008.

33. Clark JC, Dass CR and Choong PF: A review of clinical and molecular prognostic factors in osteosarcoma. J Cancer Res Clin Oncol 134: 281-297, 2008.

34. Kerbel RS: Tumor angiogenesis: Past, present and the near future. Carcinogenesis 21: 505-515, 2000

35. Maione F and Giraudo E: Tumor angiogenesis: Methods to analyze tumor vasculature and vessel normalization in mouse models of cancer. Methods Mol Biol 1267: 349-365, 2015.

36. Kubota Y: Tumor angiogenesis and anti-angiogenic therapy. Keio J Med 61: 47-56, 2012.

37. Klinger P, Surmann-Schmitt C, Brem M, Swoboda B, Distler JH, Carl HD, von der Mark K, Hennig FF and Gelse K: Chondromodulin 1 stabilizes the chondrocyte phenotype and inhibits endochondral ossification of porcine cartilage repair tissue. Arthritis Rheum 63: 2721-2731, 2011.

38. Miura S, Kondo J, Kawakami T, Shukunami C, Aimoto S, Tanaka $\mathrm{H}$ and Hiraki $\mathrm{Y}$ : Synthetic disulfide-bridged cyclic peptides mimic the anti-angiogenic actions of chondromodulin-I. Cancer Sci 103: 1311-1318, 2012.

39. Liang CC, Park AY and Guan JL: In vitro scratch assay: A convenient and inexpensive method for analysis of cell migration in vitro. Nat Protoc 2: 329-333, 2007. 